\title{
ANALISIS KOMPARASI METODE ALTMAN Z-SCORE - FINANCIAL RATIO DAN METODE BENEISH M-SCORE MODEL - DATA MINING DALAM MENDETEKSI FRAUDULENT FINANCIAL REPORTING
}

\author{
Hendang Tanusdjaja ${ }^{1}$, Fanny Magdalena Kurniawan ${ }^{2}$ \\ ${ }^{1}$ Fakultas Ekonomi Universitas Tarumanagara Jakarta \\ Email: hendangt@gmail.com \\ ${ }^{2}$ Fakultas Ekonomi Universitas Tarumanagara Jakarta \\ Email: fan_magdalena@yahoo.com
}

\begin{abstract}
ABSTRAK
Riset ini mencoba untuk menginvestigasi metode manakah diantara, Altman Z Score - Financial Ratio and metode Beneish M-Score Model - Data Mining, yang mendeteksi secara signifikan terhadap Fraudulent Financial Reporting dengan menggunakan analisis komparasi diantara metodologi yang diatas. Kami berargumentasi bahwa kedua metode tersebut dapat digunakan untuk mendekteksi Fraudulent Financial Reporting pada perusahan terbuka. Hal tersebut diasumsikan bahwa laporan keuangan dibuat sedemikian rupa sebelum dipublikasikan kepada pihak luar dalam rangka penggunaan untuk tujuan tertentu. Oleh karena itu, riset ini memformulasikan sebuah analisis komparasi metode untuk mendeteksi fraudulent financial reporting. Secara logika, penelitian ini menunjukkan suatu hipotesis dimana semakin tinggi hubungan antara metode dengan indikator rasio, maka metode tersebut semakin signifikan dalam mendektesi secara positif terhadap fraudulent financial reporting. Oleh karena itu, kami melakukan uji hipotesis ini pada industri sektor barang konsumsi dengan menggunakan data dari IDX dan dijalankan dengan PLS - SEM. Hasil uji telah membuktikan bahwa hipotesis di atas dapat mendeteksi fraudulent financial reporting, akan tetapi metode Altman Z Score - Financial Ratio lebih berpengaruh dalam mendeteksi fraudulent financial reporting daripada metode Beneish M-Score Model.
\end{abstract}

Kata kunci: kecurangan, keuangan, Altman Z Score, rasio keuangan, Beneish M-Score, data mining

\section{PENDAHULUAN}

Kasus kecurangan terhadap laporan keuangan banyak terjadi, diantaranya pada perusahaan go public, seperti yang terjadi pada Toshiba Corporation di Jepang pada tahun 2015, dimana terjadi penggelembungan keuntungan senilai 1,2 milyar USD sejak tahun fiskal 2008 (Suminar, 2017). Kasus kecurangan terhadap laporan keuangan juga terjadi pada PT Kimia Farma Tbk di Indonesia tahun 2001 dengan penggelembungan laba bersih pada laporan keuangannya sebesar 32,6 milyar rupiah (Parsaoran, 2017). Selain itu, dugaan kecurangan yang terjadi pada PT Timah (Persero) Tbk, dimana perusahaan diduga menyerahkan laporan keuangan fiktif pada semester pertama tahun 2015, bahkan terjadi pada PT Cakra Mineral Tbk, kasus penggelapan dan manipulasi akuntansi pada pengelembungan asset dan melebihkan nilai modal disetor. Oleh sebab itu, pendeteksian pada Fraudulent Financial Reporting sangatlah penting, supaya pihak yang berkepentingan, dalam hal ini adalah investor memiliki tingkat kewaspadaan dan dapat mengambil keputusan yang tepat dalam melakukan investasi di suatu perusahaan.

Jika demikian, dalam jurnal ini ingin membandingkan dua metode deteksi fraudulent financial reporting yang telah diteliti sebelumnya, yaitu dengan metode financial ratio - Z-Score dan Metode Beneish M-Score - Data Mining untuk melihat pengaruh kedua metode tersebut dalam mendeteksi fraudulent financial reporting pada sektor industri perusahan manufaktur barang komsumsi tahun $2012-2016$. 


\section{Teori Agensi}

Kecurangan - kecurangan yang terjadi pada perusahaan Go Public yang disebutkan pada pendahuluan sejalan dengan teori Agency, di mana terdapat motivasi dari manajemen sebagai agen untuk menampilkan kinerja yang baik bagi pemegang saham yang dalam hal ini merupakan prinsipal. Teori Agency yang dikemukakan oleh Jensen dan Meckling (1976) mengatakan bahwa agen berusaha memenuhi target yang diberikan oleh prinsipal untuk mencapai insentif yang maksimal.

\section{Teori Pentagon}

Terjadinya fraudulent financial reporting yang dilakukan oleh agen, juga sesuai dengan teori Pentagon dari Crowe (2011), bahwa dalam melakukan kecurangan, agen dipicu oleh kesempatan (opportunity), tekanan (pressure), rasionalisasi (rationalization), kemampuan (competence), dan arogansi (arrogance). Cara untuk mendeteksi fraudulent financial reporting adalah dengan menggunakan metode Altman Z-Score - Financial Ratio dan Beneish M-Score Model - Data Mining.

\section{Altman Z Score - Financial Ratio}

Salah satu cara mendeteksi fraudulent financial reporting adalah dengan metode rata - rata rasio keuangan. Rasio keuangan sendiri digunakan untuk mengukur kemampuan kinerja perusahaan. Dalam journal Accountability in financial reporting: detecting fraudulent firms , oleh Hawariah Dalniala, Amrizah Kamaluddina, Zuraidah Mohd Sanusia and Khairun Syafiza Khairuddin, 5 jenis rasio yang mereka teliti terdiri dari:

\section{Financial Leverage}

Dihitung dengan cara membagi Total Debt dengan Total Equity dan Total Debt dibagi dengan Total Asset. Tingginya tingkat leverage sering diasosiasikan dengan potensi yang lebih tinggi terjadinya penyimpangan terhadap perjanjian pinjaman dan mengurangi kemampuan untuk mendapatkan modal tambahan melalui pinjaman. Disimpulkan oleh Christie (1990), leverage dikorelasikan dengan kebijakan akuntansi untuk menaikkan income.

\section{Profitability}

Profitability diukur dengan Laba bersih dibagi pendapatan. Menurut Kreudfelt and Wallace (1986) , perusahaan yang memiliki masalah dengan laba, memiliki kesalahan yang lebih signifikan dalam laporan keuangan mereka daripada perusahaan lain.

\section{Asset Composition}

Cara mengukur asset composition adalah dengan:

a. membagi Current Asset dengan Total asset

b. membagi piutang/receivables dengan revenue

c. membagi persediaan/inventory dengan total asset

Investigasi perusahaan dengan kecurangan pada laporan keuangan mengindikasikan bahwa dalam perusahaan ini lebih banyak terjadi pada aktiva lancar yaitu piutang dan persediaan.

\section{4. $\quad$ Liquidity}

Mengukur likuiditas dengan membagi working capital dengan total asset. Tingkat likuiditas yang rendah dapat menjadi alasan bagi manajer untuk melakukan kecurangan pada laporan keuangan, agar laporan keuangan terlihat baik dari segi likuiditas. 


\section{Capital Turnover}

Capital turnover diukur dengan membagi revenue/ pendapatan dengan total asset. Perputaran ini menggambarkan kekuatan sales dari sumber harta perusahaan. Capital turnover juga mengukur kemampuan manajemen untuk "deal" dengan situasi yang kompetitive.

\section{Overall financial position, digunakan Z-Score}

Keadaan terjadinya financial distress menjadi motivasi bagi manajemen untuk melakukan fraudulent fraud reporting. Keadaan keuangan perusahaan yang kurang baik dapat menjadi dorongan bagi orang dalam perusahaan untuk mengambil langkah menjadikan laporan keuangan yang cantik. Hal ini dapat diukur dengan $\mathrm{Z}$ - Score. Z-Score mengukur nilai kebangkrutan dari suatu perusahaan, diukur dengan rumus sebagai berikut:

$\mathrm{Z}=1.2$ (working capital/total assets) +1.4 (retained earnings/total assets) +3.3 (EBIT/Total Assets $)+0.06$ (Market value of equity/ book value of total debt $)+1.0$ (sales/total assets)

Perusahaan yang memiliki nilai Z-Score $>2,99$ dinilai sebagai perusahaan yang sehat dan yang memiliki nilai antara 1,81 hingga 2,99 dinilai sebagai perusahan yang berada pada grey area, sedangkan yang memiliki nilai di bawah 1,81 dinilai sebagai perusahaan yang memiliki potensi kebangkrutan.

\section{Beneish M-Score Model - Data Mining}

Metode ini dapat digunakan untuk mendeteksi perusahaan yang memiliki kecenderungan untuk melakukan fraud pada laporan keuangan mereka. Secara empiris, perusahaan dengan nilai tingkat M-Model yang lebih tinggi memiliki kecenderungan lebih besar untuk melakukan fraud. Beneish M-Score Model merupakan model probabilitas, dimana salah satu keterbatasannya adalah kemampuan mendeteksi fraud yang tidak $100 \%$ akurat. Rumus dari metode Beneish M-Score Model adalah:

$$
\begin{aligned}
& \mathrm{M}=-4.840+0,920 \mathrm{DSRI}+0,528 \mathrm{GMI}+0,0404 \mathrm{AQI}+0,892 \mathrm{SGI}+0,115 \mathrm{DEPI}-0,172 \mathrm{SGAI} \\
& + \text { 4,679 TATA- } 0,327 \mathrm{XLVGI}
\end{aligned}
$$

\section{Dimana:}

- $\quad$ DSRI = Days Sales in Receivables Index

- $\quad \mathrm{GMI}=$ Gross Margin Index

- $\quad$ DEPI = Depreciation Index

- $\quad$ SGI = Sales Growth Index

- $\quad$ LVGI = Leverage Index

- $\quad$ TATA = Total Accruals to Total Assets

- $\quad$ AQI = Asset Quality Index

- $\quad$ SGAI = Sales, General and Administrative Expenses Index

Bila nilai M-Score > -2.22 menandakan bahwa ada indikasi terjadi financial fraud pada perusahaan tersebut. Beneish M-Model digunakan oleh Data Mining untuk mengukur perusahaan yang melakukan kecurangan. Teknik Data Mining yang digunakan adalah Logit Regression.

\section{Komparasi Metode Altman Z Score - Financial Ratio dan Beneish M-Model - Data Mining}


Kecurangan yang terjadi didalam laporan keuangan dapat dideteksi dengan kedua metode yang telah di uraikan diatas, sehingga pada sesi ini perlu adanya sebuah komparasi diantara kedua metode agar dapat terlihat perbedaan diantara kedua metode, yaitu 'Metode Altman Z-Score Financial Ratio dan Metode Beneish M-Score - Data Mining.'

Tabel 1. Tabel Komparasi Metode Altman Z-Score - Financial Ratio dan Metode Beneish MScore - Data Mining

\begin{tabular}{|c|c|c|}
\hline & $\begin{array}{c}\text { Metode Altman Z-Score - Financial } \\
\text { Ratio } \\
\end{array}$ & $\begin{array}{c}\text { Metode Beneish M-Score - Data } \\
\text { Mining }\end{array}$ \\
\hline Penggunaan & $\begin{array}{c}\text { Dalam penggunaan metode Altman } \\
\text { Z-Score untuk mendeteksi } \\
\text { fraudulent financial reporting } \\
\text { menggunakan beberapa rasio } \\
\text { dalam memprediksi kebangkrutan } \\
\text { berdasarkan rasio likuiditas, } \\
\text { profitabilitas, leverage dan } \\
\text { solvency yang dimasukkan dalam } \\
\text { sebuah rumus yang disebut Z-Score }\end{array}$ & $\begin{array}{c}\text { Penggunaan metode Beneish M - } \\
\text { Score dalam mendekteksi } \\
\text { fraudulent financial reporting yaitu } \\
\text { melihat dari sisi manipulasi laba } \\
\text { dengan membandingkan kunci } \\
\text { Beneish dalam standard GAAP } \\
\text { Violation. }\end{array}$ \\
\hline $\begin{array}{l}\text { Penggunaan } \\
\text { Data }\end{array}$ & $\begin{array}{l}\text { Metode Altman Z - Score dapat } \\
\text { menggunakan data laporan } \\
\text { keuangan satu tahun buku saja }\end{array}$ & $\begin{array}{l}\text { Metode Beneish } \mathrm{M} \text { - Score minimal } \\
\text { menggunakan data laporan dua } \\
\text { tahun buku }\end{array}$ \\
\hline Jenis Ratio & $\begin{array}{l}\text { Jenis rasio yang dipakai pada } \\
\text { metode Altman Z-Score - Financial } \\
\text { Ratio adalah financial leverage, } \\
\text { Profitability, Assest Composition, } \\
\text { Liquidity dan Capital Turn Over plus } \\
\text { Z Score. }\end{array}$ & $\begin{array}{c}\text { Jenis rasio yang dipakai pada } \\
\text { metode Beneish M-Score - Data } \\
\text { Mining adalah Days Sales } \\
\text { inreceivable, depresition, sales } \\
\text { growth, leverage, total accruals to } \\
\text { total assests, gross margin, assest } \\
\text { quality, sales general \& } \\
\text { administrative expense. }\end{array}$ \\
\hline $\begin{array}{l}\text { Rentang } \\
\text { Waktu } \\
\text { Penggunaan }\end{array}$ & $\begin{array}{c}\text { Metode Altman Z-Score - Financial } \\
\text { Ratio digunakan sudah lebih } 30 \\
\text { tahun. }\end{array}$ & $\begin{array}{c}\text { Metode Beneish M-Score - Data } \\
\text { Mining digunakan sejak tahun } \\
1999 .\end{array}$ \\
\hline Akurasi & $\begin{array}{c}\text { Metode ini tidak memiliki } \\
\text { keakuratan } 100 \%\end{array}$ & $\begin{array}{l}\text { Metode ini tidak memiliki } \\
\text { keakuratan } 100 \%\end{array}$ \\
\hline
\end{tabular}




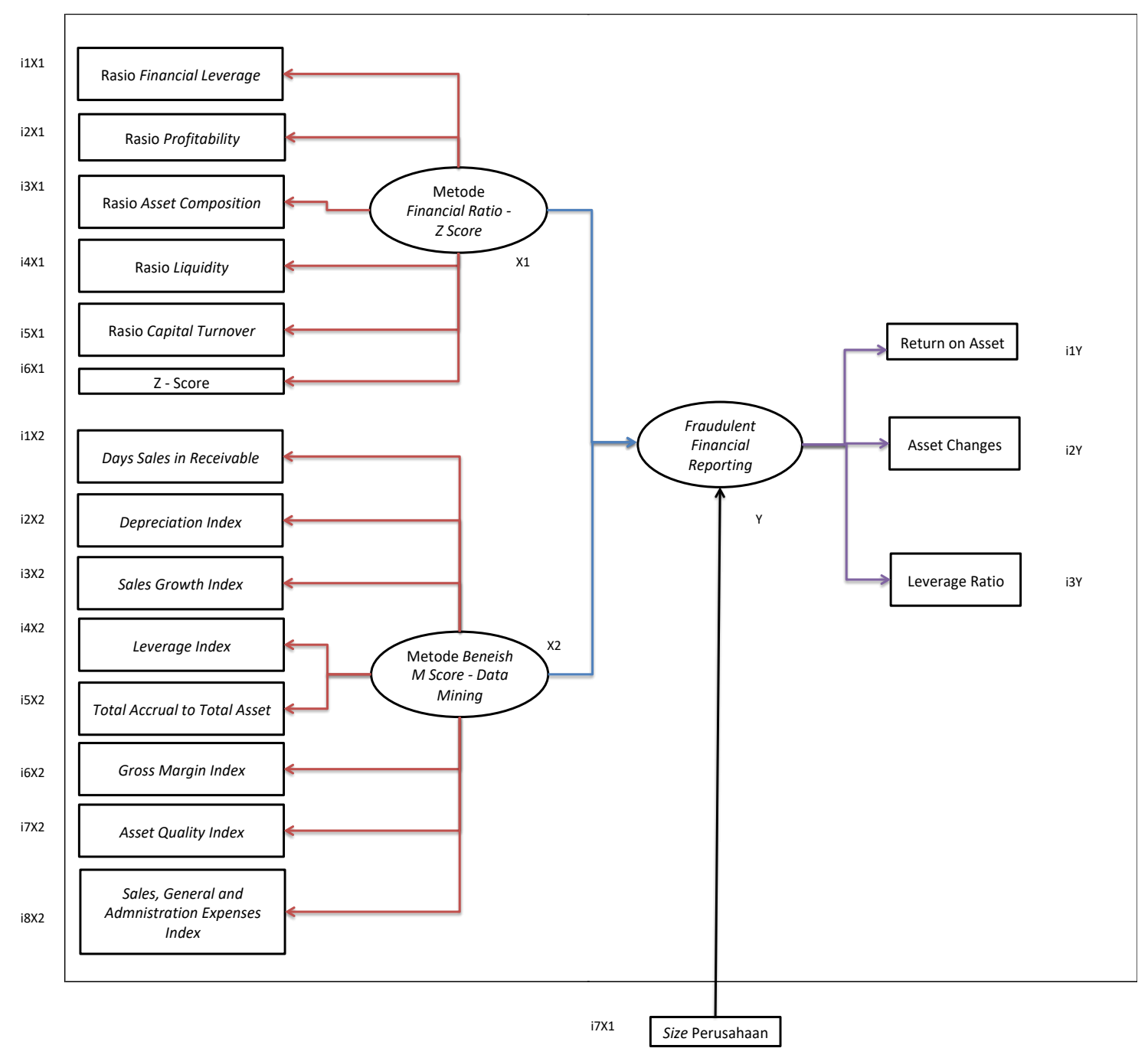

Gambar 1. Skema Kerangka Pemikiran

Hipotesis. Berdasarkan kerangka pemikiran di atas, maka hipotesis penelitian ini adalah:

H1 : Metode Altman Z-Score - Financial Ratio berpengaruh secara positif dalam mendeteksi fraudulent financial reporting

$\mathrm{H} 2$ : Metode Beneish M-Score Model - Data Mining berpengaruh secara positif dalam mendeteksi fraudulent financial reporting

\section{METODE}

\section{Teknik Penarikan Sampling}

Pada penelitian ini menggunakan desain penelitian deskriptif yang bersifat kuantitatif, di mana penelitian dilakukan pada perusahaan Manufaktur Go Public sektor industri barang konsumsi antara rentang waktu 2012 hingga 2016, di mana data yang digunakan adalah data dari idx.co.id, dengan kriteria perusahaan go public yang telah terdaftar di bursa selama lebih dari 17 tahun atau yang listing pada tahun 1997 dan sebelumnya, serta perusahaan yang tidak melakukan stock split maupun stock reverse diantara tahun penelitian yaitu tahun 2012 hingga 2016. Data sampel yang digunakan adalah 15 perusahaan untuk 5 tahun atau sebanyak 75 sampel.

\section{Variabel Eksogenus, Endogenus dan Kotrol}

Variabel penelitian ini terdiri dari variabel eksogenus, endogenus dan kontrol yang dijabarkan dalam tabel di bawah ini: 
Tabel 2. Variabel Eksogenus, Endogenus dan Kontrol

\begin{tabular}{|c|c|c|c|}
\hline Objek Penelitian & Rumus & Variabel \& Indikat & \\
\hline Altman Z - Score - Financial Ratio & & Variabel Laten Eksogonus & $\mathrm{X} 1$ \\
\hline Financial Leverage Ratio & FL = Total Debt/ Total Equity & Indikator & $\mathrm{i} 1 \mathrm{X1}$ \\
\hline Profitability Ratio & Profitability = Net Profit/ Revenue & Indikator & $12 \times 1$ \\
\hline Asset Composition Ratio & $A C=$ Receivable/ Revenue & Indikator & i3X1 \\
\hline Liquidity Ratio & Liquidity = Working Capital / Total Asset & Indikator & i4X1 \\
\hline Capital Turnover Ratio & CT = Revenue $/$ Total Asset & Indikator & $15 \times 1$ \\
\hline Altman Z - Score & $\begin{array}{l}Z=1.2 \text { (working Capital/total Asset)+1.4(retained } \\
\text { earnings/total assets)+3.3(EBIT/Total } \\
\text { Assets)+0.06(market value of equity/book value of } \\
\text { total debt)+1.0 (sales/total assets) }\end{array}$ & Indikator & $16 \times 1$ \\
\hline Size Perusahan & Natural Logarithm of book value of total assets & Indikator & i7X1 \\
\hline Beneish M-Score - Data Mining & & Variabel Laten Eksogonus & $X 2$ \\
\hline Day Sales in Receivable & DSRI = (Net ARt/Salest) / (Net Art-1/Salest-1) & Indikator & $i 1 \times 2$ \\
\hline Depreciation Index & $\begin{array}{l}\text { DEPI = (Deprt-1/(PP\&Et-1+Deprt- } \\
\text { 1))/(Deprt/(PP\&Et+Deprt)) }\end{array}$ & Indikator & $i 2 \times 2$ \\
\hline Sales Growth Index & SGI = Salest $/$ Salest -1 & Indikator & $13 \times 2$ \\
\hline Leverage Index & $\begin{array}{l}\text { LVGI }=((C L t+\text { Long term Debt } \mathrm{t}) / \text { Total Asset } \mathrm{t}) /(\text { CLt- } \\
1+\text { Longterm debt } \mathrm{t}-1) / \text { Total asset } \mathrm{t}-1))\end{array}$ & Indikator & $14 \times 2$ \\
\hline Total Accrual to Total Asset & $\begin{array}{l}\text { TATA }=(\text { Income form Continuing Operation } \mathrm{t} \text { - cash } \\
\text { flow from operations } \mathrm{t}) / \text { Total Asset } \mathrm{t}\end{array}$ & Indikator & $i 5 \times 2$ \\
\hline Gross Margin Index & $\begin{array}{l}\text { GMI = }((\text { Sales } t-1-\text { COGS } t-1) / \text { Sales } t-1)) /((\text { Sales t- } \\
\text { COGS } t) / \text { Sales } t))\end{array}$ & Indikator & $i 6 \times 2$ \\
\hline Asset Quality Index & $\begin{array}{l}\text { AQI }=(1-((\text { Current asset t+PP\&Et+Securities } t) / \text { Total } \\
\text { asset } t)) /(1-((\text { Current asset t-1+PP\&E } t-1+\text { Securities t- } \\
1) / \text { Total asset } t-1))\end{array}$ & Indikator & $i 7 \times 2$ \\
\hline $\begin{array}{l}\text { Sales, General \& Administration } \\
\text { Expense Index }\end{array}$ & $\begin{array}{l}\text { SGAI = (SG\&A expense t/Sales } t) /(\text { SG\&A expense t- } \\
1 / \text { sales } t-1)\end{array}$ & Indikator & i8X2 \\
\hline Fraudulent Financial Reporting & & Variabel Laten Endogonus & $Y$ \\
\hline Return On Asset & ROA = NI/ Total Asset & Indikator & i1Y \\
\hline Asset Changes & $\begin{array}{l}\text { Asset Changes }=(\text { total asset } \mathrm{t} \text { - total asset } \mathrm{t}-\mathrm{1}) / \text { total } \\
\text { asset } \mathrm{t}-1\end{array}$ & Indikator & $\mathrm{i} 2 \mathrm{Y}$ \\
\hline Leverage & LEV = Liabilities/ total asset & Indikator & i3Y \\
\hline
\end{tabular}

\section{Model Regresi}

Berdasarkan kerangka konseptual penelitian berdasarkan model persamaan struktural dengan menggunakan PLS - SEM maka persamaan yang dirumuskan adalah sebagai berikut:

$$
\eta=\gamma 1 \xi 1+\gamma 2 \xi 2+\zeta
$$

FFR $=\gamma 1$ metode Altman Z-Score - Financial Ratio. $+\gamma 2$ metode Beneish M-Score - Data Mining $+\zeta$ (zeta / tingkat kesalahan struktural)

\section{HASIL DAN PEMBAHASAN \\ Koefisien Jalur - R-Square}




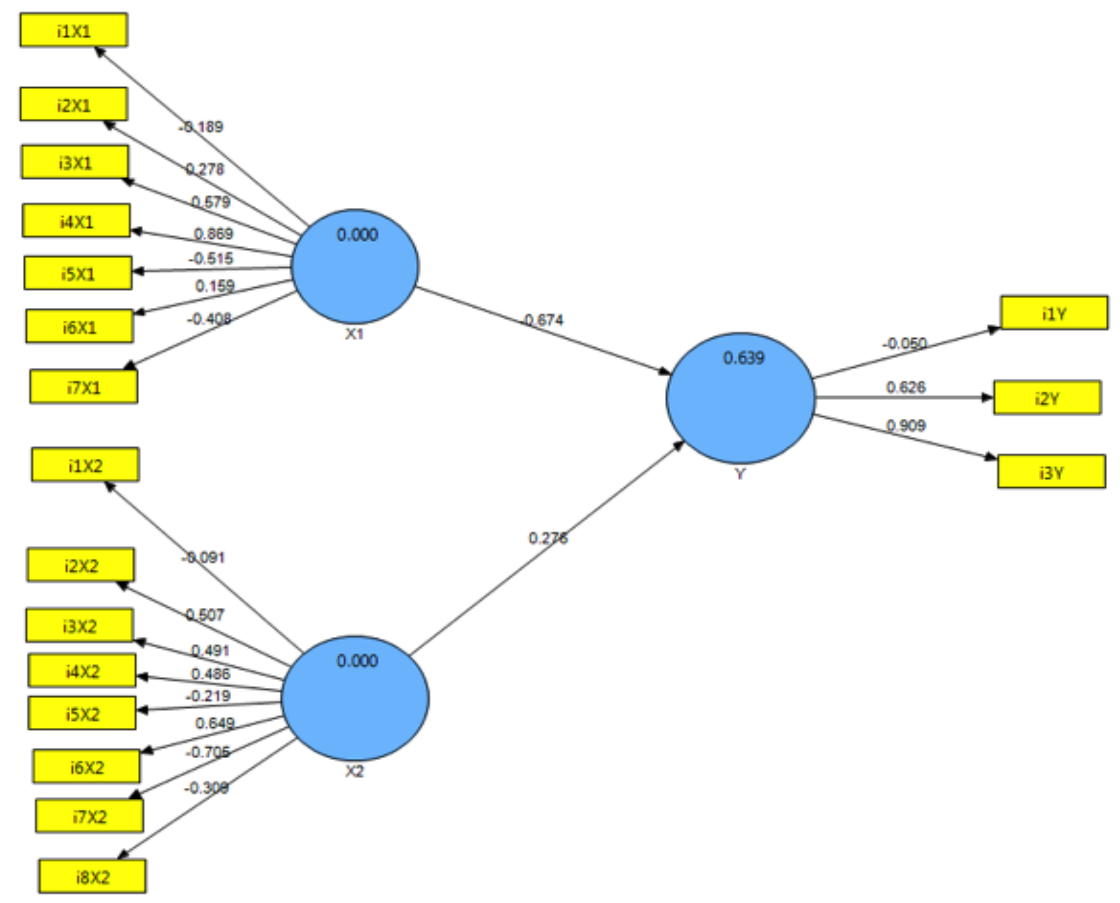

Gambar 2. Diagram jalur persamaan struktural PLS dengan software Smart PLS

Tabel 3. Tabel Koefisien Jalur

\section{Path Coefficients}

\begin{tabular}{|c|c|c|c|}
\hline & $\mathbf{X 1}$ & $\mathbf{X 2}$ & $\mathbf{Y}$ \\
\hline $\mathbf{X 1}$ & & & -0.674162 \\
\hline $\mathbf{X 2}$ & & & 0.276432 \\
\hline $\mathbf{Y}$ & & & \\
\hline
\end{tabular}

\section{Koefisien Jalur dari Variabel Laten X1 ke Variabel Laten Y}

- Koefisien jalur dari X1 ke Y sebesar 0,674 (dari diagram jalur) atau 0,674162 (dari keluaran teks). Nilai ini mempunyai makna besarnya pengaruh variabel laten X1 terhadap variabel laten $\mathrm{Y}$ sebesar 0.674 .

\section{Koefisien Jalur dari Variabel Laten X2 ke Variabel Laten Y}

- Koefisien jalur dari X2 ke Y sebesar 0,276 (dari diagram jalur) atau 0,276432 (dari keluaran teks). Nilai ini mempunyai makna besarnya pengaruh variabel laten $\mathrm{X} 2$ terhadap variabel laten $\mathrm{Y}$ sebesar 0,276 .

Berdasarkan hasil koefisien jalur, maka model persamaan struktural adalah sebagai berikut: FFR = 0,674 metode Altman Z-Score - Financial Ratio. + 0,276 metode Beneish M-Score - Data Mining + $\zeta$ (zeta / tingkat kesalahan struktural) 
Tabel 4. Tabel $\mathrm{R}$ - square

\section{R Square}

\begin{tabular}{|c|c|}
\hline & R Square \\
\hline $\mathbf{X 1}$ & \\
\hline $\mathbf{X 2}$ & \\
\hline $\mathbf{Y}$ & 0.638545 \\
\hline
\end{tabular}

Nilai R square dari Variabel Laten X1 dengan indikator - indikatornya dan Variabel Laten 2 dengan indikator - indikatornya ke Variabel Laten Y.

Nilai R square dari variabel laten X1 dengan indikator - indikatornya dan variabel laten X2 dengan indikator - indikatornya ke variabel laten Y sebesar 0,639 (dari diagram jalur) atau 0,638545 (dari keluaran teks). Nilai ini mempunyai makna besarnya pengaruh variabel laten X1 dengan indikator - indikatornya dan variabel laten X2 dengan indikator - indikatornya ke variabel laten Y sebesar 0,639 .

Uji Validitas dan Reliabilitas. Uji validitas dilihat dari Average Variance Extracted (AVE) sebagai berikut:

Tabel 5. Tabel teks Average Variance Extracted (AVE)

Average Variance Extracted (AVE)

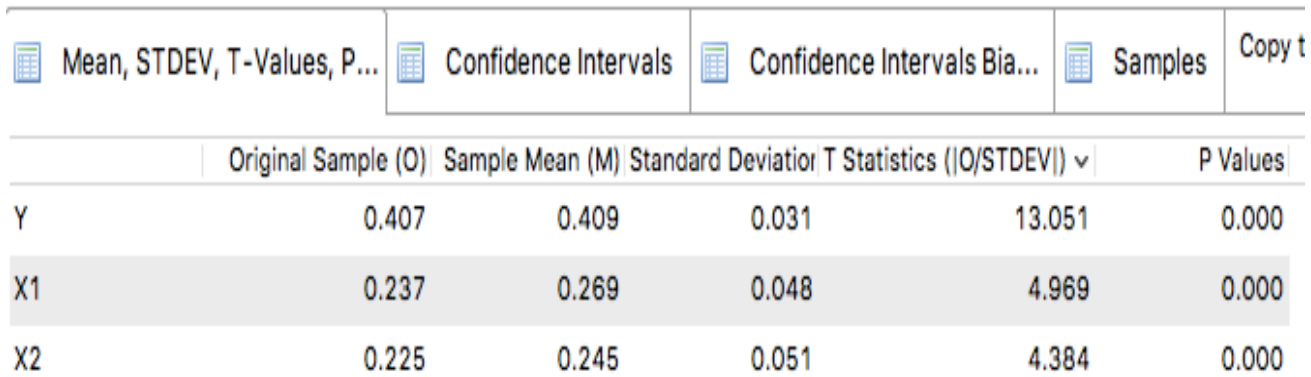

- Nilai AVE untuk variabel laten X1 sebesar 0,237 dengan P values 0,000 mempunyai makna bahwa variabel laten X1 sudah memenuhi persyaratan validitas konvergen. Hal ini mempunyai pengertian bahwa variabel laten tersebut sudah mewakili indikator - indikator dalam bloknya.

- Nilai AVE untuk variabel laten X2 sebesar 0,225 dengan P values 0,000 mempunyai makna bahwa variabel laten X2 sudah memenuhi persyaratan validitas konvergen. Hal ini mempunyai pengertian bahwa variabel laten tersebut sudah mewakili indikator - indikator dalam bloknya.

- Nilai AVE untuk variabel laten Y sebesar 0,407 dengan P values 0,000 mempunyai makna bahwa variabel laten X1 sudah memenuhi persyaratan validitas konvergen. Hal ini mempunyai pengertian bahwa variabel laten tersebut sudah mewakili indikator - indikator dalam bloknya.

Sedangkan untuk uji reliabilitas diperoleh dari outer model dibawah ini: 
Tabel 6. Tabel Outer Model (weights or loadings) Outer Model (Weights or Loadings)

\begin{tabular}{|c|c|c|c|}
\hline & $\mathbf{x 1}$ & $\mathbf{x 2}$ & $\mathbf{Y}$ \\
\hline i1X1 & -0.189236 & & \\
\hline i1x2 & & -0.091344 & \\
\hline i1Y & & & -0.050158 \\
\hline i2X1 & 0.277580 & & \\
\hline$i 2 \times 2$ & & 0.506572 & \\
\hline $\mathrm{i} 2 \mathrm{Y}$ & & & 0.626277 \\
\hline i3x1 & 0.578540 & & \\
\hline$i 3 \times 2$ & & 0.490797 & \\
\hline i3Y & & & 0.908761 \\
\hline$i 4 \times 1$ & 0.869161 & & \\
\hline$i 4 \times 2$ & & 0.486240 & \\
\hline i5x1 & -0.514984 & & \\
\hline$i 5 \times 2$ & & -0.218816 & \\
\hline$i 6 \times 1$ & 0.159225 & & \\
\hline $16 \times 2$ & & 0.648877 & \\
\hline$i 7 \times 1$ & -0.408107 & & \\
\hline$i 7 \times 2$ & & -0.704616 & \\
\hline $18 \times 2$ & & -0.308561 & \\
\hline
\end{tabular}

Menurut hasil tabel outer model dapat disimpulkan bahwa:

- Indikator - indikator variabel laten X1 sudah reliabel

- Indikator - indikator variabel laten X2 sudah reliabel

- Indikator - indikator variabel laten Y sudah reliabel

Hasil Uji Hipotesis. Dari hasil uji yang dilakukan, maka diperoleh hasil sebagai berikut:

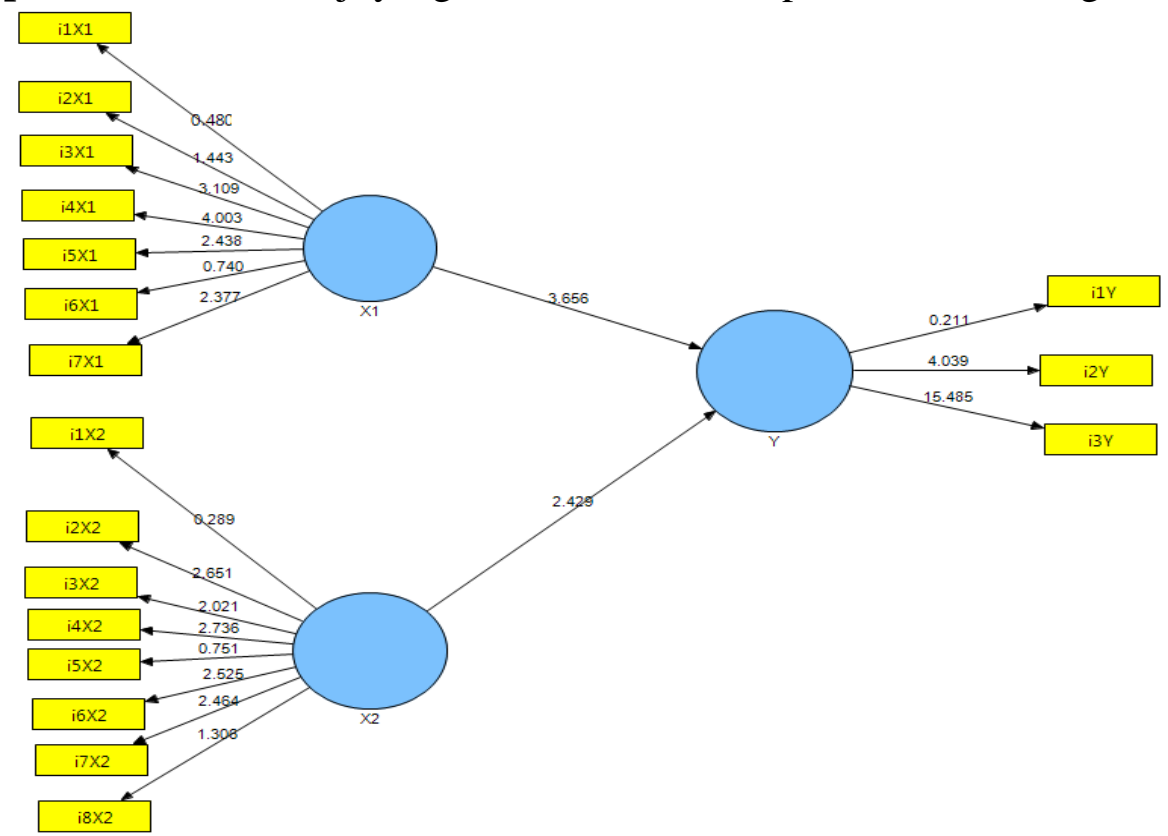

\section{Gambar 3. Diagram jalur persamaan struktural PLS dengan software Smart PLS}

Setelah pengujian komponen diatas, maka dilakukan uji terhadap dua hipotesis pada bagian 3.1 di atas, yaitu metode Altman Z-Score - Financial Ratio berpengaruh secara positif dalam mendeteksi fraudulent financial reporting dan metode Beneish M-Score - Data Mining berpengaruh secara positif dalam mendeteksi fraudulent financial Reporting. 


\section{Pembahasan}

Dari hasil uji asumsi yang telah dilakukan di atas menggunakan PLS-SEM, telah diperoleh hasil sebagai berikut:

a. Hipotesis 1: metode Altman Z-Score - Financial Ratio berpengaruh secara positif dalam mendeteksi fraudulent financial reporting.

Menurut uji asumsi di atas, diperoleh hasil koefisien jalur sebesar negatif 0,674, dimana koefisien ini menunjukkan besarnya pengaruh variabel laten metode Altman Z-Score - Financial Ratio terhadap variabel laten fraudulent financial reporting sebesar 0,674. Tanda negatif pada koefisien jalur hanya menandakan arah hubungan korelasi yang terbalik, di mana kenaikan variabel metode Altman Z-Score - Financial Ratio akan diikuti dengan turunnya nilai fraudulent financial reporting. Akan tetapi nilai sebesar 0,674 menunjukkan kuatnya korelasi/hubungan antara variabel laten metode Altman Z-Score - Financial Ratio dengan fraudulent financial reporting (Sarwono, 2018). Sedangkan untuk tingkat signifikansi, diperoleh nilai 3,656 menurut $t$ hitung, sementara $t$ tabel adalah senilai 1,66543, artinya variabel laten metode Altman Z-Score - Financial Ratio berpengaruh secara positif terhadap fraudulent financial reporting. Hal ini sejalan dengan penelitian yang dilakukan oleh Hawariah Dalnial,dkk dimana terdapat perbedaan nilai yang signifikan dari Altman Z-Score - Financial Ratio terhadap perusahaan yang mengalami kecurangan dan yang tidak, dimana penelitian mereka menunjukkan bahwa rasio finansial dan $\mathrm{z}-$ score berpengaruh secara signifikan dalam mendeteksi fraudulent financial reporting (Dalnial dkk, 2016). Hasil uji asumsi di atas telah sejalan dengan penelitian terdahulu bahwa variabel metode Altman Z-Score - Financial Ratio berpengaruh secara postif terhadap fraudulent financial reporting.

Variabel laten Altman Z-Score - Financial Ratio dengan masing - masing indikatornya sesuai dengan penelitian sebelumnya, bila dipisahkan satu persatu, maka tiap indikator memiliki pengaruh masing - masing terhadap variabel latennya, seperti tergambar dalam tabel di bawah ini:

Tabel 7. Perbandingan Teori dan Hasil uji hipotesis setiap indikator X1 ke Y

\begin{tabular}{|l|c|c|c}
\cline { 3 - 4 } \multicolumn{1}{c|}{} & \multirow{2}{*}{ Teori } & \multicolumn{2}{c}{ Hasil Uji Hipotesis } \\
\cline { 3 - 4 } \multicolumn{1}{c|}{ Altman Z - Score - Financial Ratio } & & Nilai & Hasil \\
\hline Financial Leverage Ratio & Signifikan & 1,755439368 & Signifikan \\
\hline Profitability Ratio & Tidak Signifikan & 5,276152744 & Signifikan \\
\hline Asset Composition Ratio & Tidak Signifikan & 11,36492095 & Signifikan \\
\hline Liquidity Ratio & Tidak Signifikan & 14,63609405 & Signifikan \\
\hline Capital Turnover Ratio & Signifikan & 8,913298752 & Signifikan \\
\hline Altman Z - Score & Signifikan & 2,7047088 & Signifikan \\
\hline
\end{tabular}

Tabel di atas menunjukkan bahwa dari hasil uji hipotesis, seluruh indikator yaitu asset composition ratio, capital turnover ratio, financial leverage ratio, profitability ratio, liquidity ratio dan Altman Z-Score berpengaruh secara signifikan terhadap variabel laten metode Altman Z-Score - Financial Ratio. 
b. Hipotesis 2: metode Beneish M-Score - Data Mining berpengaruh secara positif dalam mendeteksi fraudulent financial Reporting.

Menurut uji asumsi di atas, diperoleh hasil koefisien jalur senilai 0,276, dimana koefisien ini menunjukkan besarnya pengaruh variabel laten metode Beneish M-Score - Data Mining terhadap variabel laten fraudulent financial reporting sebesar 0,276. Akan tetapi nilai sebesar 0,276 menunjukkan cukup kuatnya korelasi/hubungan antara variabel laten metode Beneish M-Score - Data Mining dengan fraudulent financial reporting (Sarwono, 2018). Sedangkan untuk tingkat signifikansi, diperoleh nilai 2,429 menurut t hitung, sementara t tabel adalah senilai 1,66543, artinya variabel laten metode Beneish M-Score - Data Mining berpengaruh secara positif terhadap fraudulent financial reporting. Hal ini sejalan dengan penelitian yang dilakukan oleh Tarjo dan Nurul Herawati, bahwa Metode Beneish M-Score - Data Mining memiliki kemampuan untuk mendeteksi kecurangan dalam laporan keuangan (Tarjo, 2016). Hasil uji asumsi di atas telah sejalan dengan penelitian terdahulu bahwa variabel metode Beneish M-Score - Data Mining berpengaruh secara postif terhadap fraudulent financial reporting.

c. Komparasi antara metode Altman Z-Score - Financial Ratio dan metode Beneish M-Score Data Mining

Sesuai dengan uji asumsi di atas, diperoleh hasil penelitian yang sejalan dengan penelitian sebelumya, yaitu baik metode Altman Z-Score - Financial Ratio dan Beneish M-Score - Data Mining berpengaruh secara positif dalam mendeteksi fraudulent financial reporting. Hal ini tampak dalam hasil uji t hitung yang telah dilakukan seperti dalam tabel di bawah ini:

Tabel 8. Tabel teks Inner Model T-Statistic

Inner Model T-Statistic

\begin{tabular}{|c|c|c|c|}
\hline & $\mathbf{X 1}$ & $\mathbf{X 2}$ & $\mathbf{Y}$ \\
\hline $\mathbf{X 1}$ & & & 3.655767 \\
\hline $\mathbf{X 2}$ & & & 2.428718 \\
\hline $\mathbf{Y}$ & & & \\
\hline
\end{tabular}

Sesuai dengan hasil uji statistik diatas, maka didapatkan bahwa t hitung untuk metode Altman ZScore - Financial Ratio adalah sebesar 3,656, sedangkan untuk metode Beneish M-Score - Data Mining adalah sebesar 2,429. Dalam hal ini menunjukkan bahwa metode Altman Z-Score Financial Ratio lebih besar pengaruhnya daripada metode Beneish M-Score - Data Mining. Dengan kata lain, metode Altman Z-Score - Financial Ratio memiliki konsep prediktor untuk mendektesi Fraudalent Financial Reporting dengan nilai sebesar 3,656 secara pengujian statistik bila dibandingkan dengan metode Beneish M-Score - Data Mining.

Dalam komparasi diantara kedua model diatas, maka ada beberapa hal yang harus dinyatakan: Pertama, mengenai pemakaian kedua metode diatas, secara pengujian statistik, dapat mendekteksi adanya FFR, karena kedua metode tersebut mempunyai nilai yang sangat signifikan. Namun, dalam penggunaan tahun buku laporan keuangan yang akan digunakan, metode Beneish M-Score - Data Mining membutuhkan lebih banyak tahun buku daripada Altman Z-Score - Financial Ratio, misalnya jika ingin meneliti tahun buku 2015 dan 2016, maka untuk metode Beneish M-Score Data Mining membutuhkan juga data untuk tahun buku 2014.

Kedua, sekalipun keduanya, yaitu metode Altman Z-Score - Financial Ratio maupun metode Beneish M-Score - Data Mining dapat digunakan dalam mendeteksi fraudulent financial 
reporting. Dengan kata lain, kedua metode tersebut, jika dikomparasi, maka keduanya tidak memiliki keakuratan yang sama. Namun, Altman Z-Score - Financial Ratio adalah metode yang sering dipakai untuk mendektesi fraudulent financial report, karena kemudahan dalam pengambilan data dari laporan keuangan. Ketiga, metode Altman Z-Score - Financial Ratio maupun metode Beneish M-Score - Data Mining menggunakan rasio untuk memprediksi adanya fraudulent financial reporting, tetapi setiap metode mempunyai titik penelitian yang berbeda. Metode Altman Z-Score - Financial Ratio menekankan pada aspek kebangkrutan sedangkan maupun metode Beneish M-Score - Data Mining menekankan pada aspek manipulasi laba.

Dalam komparasi kedua metode tersebut, maka Altman Z-Score - Financial Ratio adalah metode yang memiliki tingkat sensitifitas untuk mendektesi terjadinya fraudulent financial report baik secara uji statistik melalui PLS - SEM maupun penggunaan secara audit umum. Namun, bukan berarti metode Beneish M-Score - Data Mining tidak memiliki sensitifitas dalam mendektesi terjadinya fraudulent financial report, tetapi tingkat pengujian melalui PLS - SEM memiliki niai yang rendah dari Altman Z-Score - Financial Ratio.

\section{Kesimpulan}

Metode Altman Z-Score - Financial ratio memiliki pengaruh yang positif dalam mendeteksi fraudulent financial reporting dan metode Beneish M-Score - Data Mining memiliki pengaruh yang positif dalam mendeteksi fraudulent financial reporting. Hal ini sejalan dengan penelitian terdahulu bahwa metode tersebut memiliki kemampuan dalam mendeteksi fraudulent financial reporting. Berdasarkan dari hasil perhitungan statistik yang telah dilakukan di bab sebelumnya, Metode Altman Z-Score - Financial Ratio memiliki pengaruh yang lebih besar daripada metode Beneish M-Score - Data Mining. Namun dalam analisis komparasi metode Beneish M-Score Data Mining menggunakan data tahun buku lebih banyak dibandingkan metode Altman Z-Score - Financial Ratio, sehingga secara komparasi Metode Altman Z-Score adalah metode favorable untuk mendektesi fraudulent financial reporting.

Saran. Setelah melakukan pengujian secara PLS - SEM dan mendapatkan hasil dari pengujian tersebut, maka ada saran yang dapat diajukan bagi penelitian selanjutnya, yaitu pertama, penggunaan data sampel yang lebih luas dan pemisahan sampel berdasarkan perusahaan yang mengalami fraud dan yang tidak mengalami fraud, sehingga hasil yang diperoleh lebih akurat dan lebih mendekati dengan penelitian sebelumnya. Selain hal tersebut, penelitian selanjutnya diperlukan, khususnya untuk mengetahui lebih lanjut indikator - indikator mana dari metode yang diteliti memiliki pengaruh yang signifikan dan dapat digunakan sebagai acuan dalam mendeteksi fraudulent financial reporting, sehingga dalam lingkup dunia kerja secara umumnya dan lingkup dunia pendidikan secara khusus, dapat menggunakannya sebagai pembanding ratio - ratio mana yang sebaiknya digunakan.

Hal kedua yang dapat disarankan berkaitan dengan penelitian yaitu dengan menambah variabel penelitian agar penelitian ini dapat dikembangkan ketingkat yang lebih tinggi. Penambahan variabel penelitian dapat dilakukan dengan dua cara, yaitu:

a. Menambah indikator pada variabel laten eksogenus (variabel bebas) agar melihat hubungan yang kuat dengan fraudulent financial reporting.

b. Menjadikan variabel endogenus saat ini, yaitu fraudulent financial reporting menjadi variabel mediating dan menambah satu variabel endogenus baru untuk penelitian yang lebih luas dalam kerangka fraudulent financial reporting. 


\section{REFERENSI}

ABDULLAHI, R. and MANSOR, N. (2015). Fraud Triangle Theory and Fraud Diamond Theory. Understanding the Convergent and Divergent For Future Research. International Journal of Academic Research in Accounting, Finance and Management Sciences, 5(4).

Aldama, r. (2017). Fraud Tree, Perkembangan Teori Penyebab Fraud dan 5 Komponen dari COSO Framework. Rezaaditaaldama.blogspot.co.id. Retrieved 16 August 2017, from https://rezaaditaaldama.blogspot.co.id/2016/11/perkembangan-teori-penyebab-fraud-dan5.html

Ali, Y., Ali, Y. and lengkapku, L. (2016). PELUANG TERJADINYA FRAUD AKIBAT MORAL HAZARD. [online] Yusronaliblogaddress.blogspot.co.id. Available at: http://yusronaliblogaddress.blogspot.co.id/2015/07/peluang-terjadinya-fraud-akibatmoral 49.html

American Institute of Certified Public Accountants (AICPA). 2012. Consideration of Fraud in a Financial Statement Audit, Statement on Auditing Standard No. 99. New York. AICPA.

Arens, A., Elder, R., \& Beasley, M. (2011). Auditing and Assurance Services (14th ed.). Prentice Hall.

Aritonang, L. (2007). Riset Pemasaran. 1st ed. Jakarta: Ghalia Indonesia.

Aris, N. A., Mohd Arif, S. M., Othman, R., \& Zain, M. M. (2015). Fraudulent financial statement detection using statistical techniques: The case of small medium automotive enterprise. Journal of Applied Business Research,31(4), 1469. Retrieved from https://search.proquest.com/docview/1699068131?accountid=45753

Assagaf, m. (2017). Creative accounting. Mohammad Fadly Assagaf. Retrieved 30 June 2017, from https://mohammadfadlyassagaf.wordpress.com/2017/04/19/creative-accounting/

Association of Certified Fraud Examiner. (2017). Report to The Nations on Occupational Fraud and Abuse. Retrieved from http://www.acfe.com/rttn2016/docs/2016-report-to-thenations.pdf

Beneish, Messod D., 1999. The Detection of Earnings Manipulation, Financial Analysts Journal, September/October, pp. 24-36.

Beneish, Messod D., 2012. Fraud Detection and Expected Return, http://papers.ssrn.com/sol3/papers.cfm? abstract_id=1998387

"Buku Lepas." Jonathansarwono.Info, 2018, http://www.jonathansarwono.info/korelasi/korelasi.htm

Christie, A. (1990). Aggregation of test statistics: An evaluation of the evidence on contracting and size hypotheses. Journal of Accounting and Economics, 12, 15-36.

Dalnial, H., Kamaluddin, A., Sanusi, Z. and Khairuddin, K. (2016). Accountability in Financial Reporting: Detecting Fraudulent Firms.

DiNapoli, Thomas P. 2010. Red Flags for Fraud. New York. State of New York Office of the State Comptroller, pp $1-14$.

DMK, M., \& lengkapku, L. (2017). Pengertian, Definisi Dan Fungsi Data Mining | Info Dan Pengertian. Globallavebookx.blogspot.co.id. Retrieved 19 March 2017, from http://globallavebookx.blogspot.co.id/2015/01/pengertian-definisi-dan-fungsi-data.html

Fraud Tree. (2017). Acfe.com. Retrieved 16 August 2017, from http://www.acfe.com/fraudtree.aspx

Han, J., \& Kamber, M. (2006). Data mining. Amsterdam: Elsevier.

Hoffer, J., PRESCOTT, M., \& McFadden, F. Modern database management. Upper Saddle River: Prentice Hall.

Journal of Accountancy. (2016). Auditors' New Procedures for Detecting Fraud. [online] Available

at: http://www.journalofaccountancy.com/issues/2002/may/auditorsnewproceduresfordetectin 


\section{gfraud.html}

Kanapickienè, R. and Grundienè, Ž. (2016). The Model of Fraud Detection in Financial Statements by Means of Financial Ratios.

Kreutzfeldt, R. and Wallace, W. (1986). Error characteristics in audit populations: Their profile and relationship to environment factors. A Journal of Practice and Theory, 5, 20-43.

Langkah Umum Principal Component Analysis. (2017). Tyang Luhtu. Retrieved 2 June 2017, from https://tyangluhtu.wordpress.com/2013/04/19/langkah-umum-principal-componentanalysis/

Mencintamu.., M. (2017). Audit Kecurangan. Kuliah Akuntansi. Retrieved 16 August 2017, from https://dwiermayanti.wordpress.com/2010/03/22/audit-kecurangan/

Mohamed, N. and Handley-Schachelor, M. (2016). Financial Statement Fraud Risk Mechanisms and Strategies: The Case Studies of Malaysian Commercial Companies

Mohamed, N. and Handley-Schachler, M. (2016). Roots of Responsibilities to Financial Statement Fraud Control.

Muslich, Mohamad. 2000. Manajemen Keuangan Modern (Analisis, Perencanaan, dan Kebijaksanaan). Jakarta: Bumi Aksara.

My journey to fraud awareness. (2017). Acfe.com. Retrieved 30 June 2017, from https://www.acfe.com/article.aspx?id=4294977890

Nia, S. H. (2015). Financial ratios between fraudulent and non-fraudulent firms: Evidence from tehran stock exchange. Journal of Accounting and Taxation, 7(3), 38-44. doi:http://dx.doi.org/10.5897/JAT2014.0166

Noor, N., Sanusia, Z., Heang, L., Iskandar, T. and Isa, Y. (2016). Fraud Motives and Opportunities Factors on Earnings Manipulations.

OJK, D., OJK, D., Keamanan, M., Jonan Jamin Harga BBM, d., \& baik, S. (2017). Direksi PT Cakra Mineral Tbk Dilaporkan ke BEI dan OJK. Beritalima. Retrieved 24 June 2017, from https://www.beritalima.com/2016/12/16/direksi-pt-cakra-mineral-tbk-dilaporkan-bei-danojk-2/

Online, M. (2017). PT Timah Diduga Buat Laporan Keuangan Fiktif. Tambang.co.id. Retrieved 24 June 2017, from https://www.tambang.co.id/pt-timah-diduga-membuat-laporankeuangan-fiktif-9640/

Pasaribu, m., pasaribu, m., \& profile, V. (2017). Pengertian dan Prinsip Fraudulent Financial Reporting. Pengertiandanartikel.blogspot.co.id. Retrieved 16 August 2017, from http://pengertiandanartikel.blogspot.co.id/2017/03/pengertian-dan-prinsip-fraudulent.html

Rahman, R. and Anwar, I. (2016). Effectiveness of Fraud Prevention and Detection Techniques in Malaysian Islamic Banks.

Roxas, M. L. (2011). Financial statement fraud detection using ratio and digital analysis. Journal of Leadership, Accountability and Ethics, 8(4), 56-66. Retrieved from https://search.proquest.com/docview/909953374?accountid=45753

Riduwan. 2005. Belajar Mudah Penelitian Untuk Guru, Karyawan dan Peneliti Pemula, Bandung : Alfabeta

Sarwono, J., \& Narimawati, U. (2015). Membuat Skripsi, Tesis, dan Disertasi dengan Partial Least Square SEM (PLS-SEM) (1st ed.). Yogyakarta: CV Andi Offset.

Sciencedirect.com. (2016). The Role and Responsibility of Auditors in Prevention and Detection of Fraudulent Financial Reporting. [online] Available at: http://www.sciencedirect.com/science/article/pii/S221256711630291X

Sekaran, U. and Bougie, R. (2013). Research Methods for Business: A Skill-Building Approach. 6 th ed.

Singleton, T., \& Singleton, A. (2010). Fraud Auditing and Forensic Accounting, 4th Edition. John Wiley \& Sons. 
Skandal Manipulasi Laporan Keuangan PT. Kimia Farma Tbk.. (2017). Davidparsaoran's Blog. Retrieved 24 June 2017, from https://davidparsaoran.wordpress.com/2009/11/04/skandalmanipulasi-laporan-keuangan-pt-kimia-farma-tbk/

Tarjo, and Herawati, N. (2016). Application of Beneish M-Score Models and Data Mining to Detect Financial Fraud.

Teorionline.wordpress.com. (2016). sampel populasi penelitian teknik sampling | TEORIONLINE. [online] Available at: https://teorionline.wordpress.com/tag/sampel-populasipenelitian-teknik-sampling/.

Teori Keagenan (Agency Theory). (2017). Randhy Ichsan. Retrieved 24 June 2017, from https://bungrandhy.wordpress.com/2013/01/12/teori-keagenan-agency-theory/

The Committee of Sponsoring Organizations of the Treadway Commission (COSO). Fraudulent Financial Reporting : 1987 - 1997, An Analysis of U.S. Public Company. 1999.

Toshiba Corporation Accounting Scandal. (2017). Suminar. Retrieved 24 June 2017, from https://minarahayu.wordpress.com/2016/05/08/toshiba-corporation-accounting-scandal/

Tuanakotta, Theodorus M. 2013. Mendeteksi Manipulasi Laporan Keuangan. Jakarta. Salemba Empat.

Turban, Aronson, \& Liang, 2005, Decision Support Systems and Intelligent Systems, 7th Edition, Prentice Hall, New Jersey.

www.coso.org. "Report of the National Commission on Fraudulent Financial Reporting." The Committee of Sponsoring Organizations of the Treadway Commission. 